\title{
Stability of Epidoxorubicin Hydrochloride in Aqueous Solutions: Experimental and Theoretical Studies
}

\author{
Agnieszka Sobczak, ${ }^{1}$ Monika A. Lesniewska-Kowiel, ${ }^{1}$ Izabela Muszalska, ${ }^{1}$ \\ Artur Firlej, ${ }^{1}$ Judyta Cielecka-Piontek, ${ }^{1}$ Szymon Tomczak, ${ }^{1}$ Bolesław Barszcz, ${ }^{2}$ \\ Irena Oszczapowicz, ${ }^{3}$ and Anna Jelińska ${ }^{1}$ \\ ${ }^{1}$ Department of Pharmaceutical Chemistry, Faculty of Pharmacy, Poznan University of Medical Sciences, \\ Grunwaldzka 6, 60-780 Poznań, Poland \\ ${ }^{2}$ Institute of Molecular Physics Polish Academy of Sciences, Smoluchowskiego 17, 60-179 Poznań, Poland \\ ${ }^{3}$ Department of Modified Antibiotics, Institute of Biotechnology and Antibiotics, Starościńska 5, 02-515 Warszawa, Poland
}

Correspondence should be addressed to Agnieszka Sobczak; asobczak@ump.edu.pl

Received 4 January 2017; Accepted 14 June 2017; Published 30 July 2017

Academic Editor: Paula G. De Pinho

Copyright (C) 2017 Agnieszka Sobczak et al. This is an open access article distributed under the Creative Commons Attribution License, which permits unrestricted use, distribution, and reproduction in any medium, provided the original work is properly cited.

\begin{abstract}
The first-order degradation kinetics of epidoxorubicin were investigated as a function of $\mathrm{pH}$, temperature, and buffers concentrations. The degradation was followed by HPLC. Buffer catalysis was observed in acetate and phosphate buffers. The $\mathrm{pH}$-rate profiles were obtained at $333,343,353$, and $363 \mathrm{~K}$. The $\mathrm{pH}$-rate expression was $k_{\mathrm{pH}}=k_{1} \times a_{\mathrm{H}^{+}} \times f_{1}+k_{2} \times f_{1}+k_{3} \times f_{2}+\left(k_{4} \times f_{2}+k_{5} \times f_{3}\right) \times a_{\mathrm{OH}^{-}}$, where $k_{1}, k_{4}$, and $k_{5}$ are the second-order rate constants $\left(\mathrm{mol}^{-1} \mathrm{~L} \mathrm{~s}^{-1}\right)$ for hydrogen ion activity and for hydroxyl ion activity, respectively, and $k_{2}$ and $k_{3}$ are the first-order constants $\left(\mathrm{s}^{-1}\right)$ for spontaneous reaction under the influence of water. Epidoxorubicin demonstrates the greatest stability in the $\mathrm{pH}$ range 3-5. The electrostatic molecular potential orbitals HOMO-LUMO were also defined in order to determine the cause of the reactivity of particular epidoxorubicin molecule domains in solutions with various $\mathrm{pH}$ values.
\end{abstract}

\section{Introduction}

Epidoxorubicin hydrochloride (EP) is the most commonly used anthracycline antitumor antibiotic consisting of a tetracyclic quinolid aglycone connected by a glycoside bond with an amino sugar-L-acosamine. The drug is structurally related to doxorubicin and the difference between them is in the stereochemistry of the C- $4^{\prime}$ hydroxyl group of the sugar moiety. Due to its structure, EP demonstrates lower cardiotoxicity and so it can be used in higher doses [1-3]. The lower efficiency and higher toxicity of drugs can be also associated with degradation during their storage or clinical use (e.g., long-term infusions). EP is produced as powder or solutions for injections and administered as long-term infusions. Therefore, it is important to investigate its stability both in the solid phase and in solutions.

The influence of temperature and relative air humidity on the stability of EP as well as of doxorubicin and daunorubicin in the solid state was previously reported $[4$, 5]. The degradation of EP in the atmosphere of increased relative air humidity was a first-order reaction depending on the substrate concentration, and in dry, hot air (RH 0\%; $393 \mathrm{~K}$ ) a reversible first-order reaction relative to the substrate concentration. The dependences $\ln k=f(1 / T)$ and $\ln k=$ $f(\mathrm{RH} \%)$ were described by the equations $\ln k=(35.1 \pm 10.9)-$ $(16250 \pm 3823)(1 / T)$ and $\ln k=(3.79 \pm 3.34) \times 10^{-2}(\mathrm{RH} \%)-$ $(12.9 \pm 2.4)$, respectively, and the kinetic and thermodynamic parameters of the above processes were calculated [4].

The photodegradation [6] and hydrolysis of EP under acidic $(0.05 \mathrm{M} ; 363 \mathrm{~K})$ and basic $(0.05 \mathrm{M} ; 303 \mathrm{~K})$ conditions [7] were first-order reactions. The photodegradation rate was inversely proportional to the concentration of the drug and rose as the solvent $\mathrm{pH}$ increased. In the case of concentrations which are used in chemotherapy $(>500 \mathrm{mcg} / \mathrm{mL})$, protection from light was not necessary [6]. 
The stability of EP was also assessed in sodium chloride solutions (0.9\% NaCl, pH 5.20 and 6.47) and in dextrose (5\%; $\mathrm{pH} 4.36)$ at $25^{\circ} \mathrm{C}, 4^{\circ} \mathrm{C}$, and $-20^{\circ} \mathrm{C}$, stored in polyvinyl chloride (PCV) minibags, which are no longer in clinical use, and in water for injections, stored at $4^{\circ} \mathrm{C}$ in polypropylene syringes [8]. The drug was stable (loss below 10\%) under the above conditions with the exception of storage in $0.9 \% \mathrm{NaCl}(\mathrm{pH}$ 6.47 ) at $25^{\circ} \mathrm{C}$, when degradation exceeding $10 \%$ was observed after 43 days. It was also found that the repeated freezing and defrosting of these solutions stored in minibags did not cause significant degradation and that polypropylene appeared to be the best material for EP storing [8].

During the storage of EP injections at $\mathrm{pH} 3$ and a temperature of $2-8^{\circ} \mathrm{C}$ for 12 months or at $25^{\circ} \mathrm{C}$ for 6 months, some degradation products were observed [9]. Three products were isolated and characterized by NMR and LC-MS/MS methods. Product I (dimer of EP) was formed due to the condensation of two EP molecules. Product III (4-(4-amino-5-hydroxy-6methyl-tetrahydro-pyran-2-yloxy)-2,5,12-trihydroxy-7-methoxy-6,11-dioxo-1,2,3,4,6,11-hexahydro-naphthacene-2-carboxylic acid hydroxymethyl ester) was produced by oxidative rearrangement of EP in the side chain under acidic conditions. After hydrolysis of the ester group of degradation product III, product IV (4-(4-amino-5-hydroxy-6-methyltetrahydro-pyran-2-yloxy)-2,5,12-trihydroxy-7-methoxy6,11-dioxo-1,2,3,4,6,11-hexahydro-naphthacene-2-carboxylic acid) was formed, which can also be directly produced due to the oxidation of the side chain of EP and the elimination of the ester moiety [9].

The literature does not refer to comprehensive kinetic studies of EP in aqueous solutions in a wide range of $\mathrm{pH}$ values and temperatures. Thus, the aim of this study was to evaluate the degradation of EP under the influence of $\mathrm{pH}$ and temperature and to develop equations permitting the estimation of kinetic and thermodynamic parameters. To separate EP and its degradation products, our previously designed HPLC method was used [4]. The geometric structure of EP molecule, FMOs orbitals (HOMO-LUMO; Highest Occupied Molecular Orbital; Lowest Unoccupied Molecular Orbital), and molecular electrostatic potential were also determined.

\section{Experimental}

2.1. Materials and Reagents. Epidoxorubicin hydrochloride was synthesized at the Department of Modified Antibiotics, Institute of Biotechnology and Antibiotics, Warsaw, Poland. Sodium laurilsulfate (A.C. reagent, Sigma-Aldrich Logistik $\mathrm{GmbH}$, Germany) and all other chemicals and solvents were obtained from Merck KGaA, Germany, and were of analytical or high-performance liquid chromatographic grade.

2.2. Chromatographic Conditions. Chromatographic separation and quantitative analysis were performed by using the HPLC method [4]. The analytical system consisted of a Shimadzu SPD-20A Prominence UV/VIS detector, a Rheodyne with a $50 \mu \mathrm{L}$ loop. An LiChrospher RP-18 column $(250 \mathrm{~mm}$ $\times 4 \mathrm{~mm}, 5 \mu \mathrm{m}$ particle size, Merck, Germany) was used as the stationary phase. The mobile phase consisted of equal volumes of acetonitrile and a solution containing $2.88 \mathrm{~g} / \mathrm{L}$ of sodium laurilsulfate and $2.25 \mathrm{~mL} / \mathrm{L}$ of phosphoric acid. The flow rate was $1.0 \mathrm{~mL} / \mathrm{min}$ and UV detection was performed at $254 \mathrm{~nm}$. As the HPLC method was previously evaluated and validated for a stability study of epidoxorubicin in the solid state [4], selectivity was examined during stability studies in aqueous solutions in this work. Papaverine hydrochloride was used as an internal standard at a concentration of $0.05 \mathrm{mg} / \mathrm{mL}$.

2.3. Kinetic Procedures. The degradation of EP in aqueous solutions was studied at $333 \mathrm{~K}, 343 \mathrm{~K}, 353 \mathrm{~K}$, and $363 \mathrm{~K}$ in the $\mathrm{pH}$ range $0.42-9.95$. The $\mathrm{pH}$ values of the reaction solutions and those of the buffer standards were measured at reaction temperatures. The $\mathrm{pH}$ values of the reaction solutions in $\mathrm{HCl}$ were calculated from the equation $\mathrm{pH}=-\log f_{\mathrm{HCl}}[\mathrm{HCl}]$. The activity coefficient $f_{\mathrm{HCl}}$ was obtained or calculated from the literature data [10]. The ionic strength of all the solutions was adjusted to $0.50 \mathrm{M}$ with a solution of sodium chloride (4 M). Solutions of the desired $\mathrm{pH}$ and ionic strength of $0.50 \mathrm{M}$ were heated to the required temperatures and then a sample of EP was added to obtain the initial concentration of $0.2 \mathrm{mg} / \mathrm{mL}$. At selected times, determined by the rate of degradation, samples of the solutions $(1.0 \mathrm{~mL})$ were collected and instantly cooled with a mixture of ice and water. Samples with $\mathrm{pH}$ above 7.5 were neutralized by using $\mathrm{HCl}$ solutions at concentrations ensuring that their $\mathrm{pH}$ was approximately 2 . To each such sample, $1.0 \mathrm{~mL}$ of the internal standard solution (papaverine hydrochloride solution) was added. $50 \mu \mathrm{L}$ of the solution samples was injected into the column. Due to the fact that anthracyclines are photolabile, all samples to be studied were protected from light.

Microsoft Excel 2000 was used for the calculation of regression parameters.

2.4. Theoretical Studies. In order to interpret the FMOs (frontier molecular orbitals) and EP, quantum-chemical calculations were performed by using the Gaussian 03 package [11]. The GaussView software was utilized to propose the initial geometry of the investigated molecules. The molecular geometries were optimized by means of a density functional theory (DFT) method with the B3LYP hybrid functional and a $6-31 G(d, p)$ basis set.

\section{Results and Discussion}

3.1. Observed Rate Constants. The observed rate constants of EP degradation in aqueous solutions were determined in a $\mathrm{pH}$ range of $0.42-9.95$ and described by the equation of a pseudo-first-order reaction:

$$
\ln c_{t}=\ln c_{0}-k_{\mathrm{obs}} \times t
$$

where $c_{t}$ and $c_{0}$ are the time-dependent concentration and the initial concentration of EP at times $t>0$ and $t=0$, respectively; $k_{\mathrm{obs}}$ is the observed rate constant of the pseudofirst-order reaction of EP degradation.

The number of measurements of $c_{t}$ for each series ranged from 8 to 12 . 


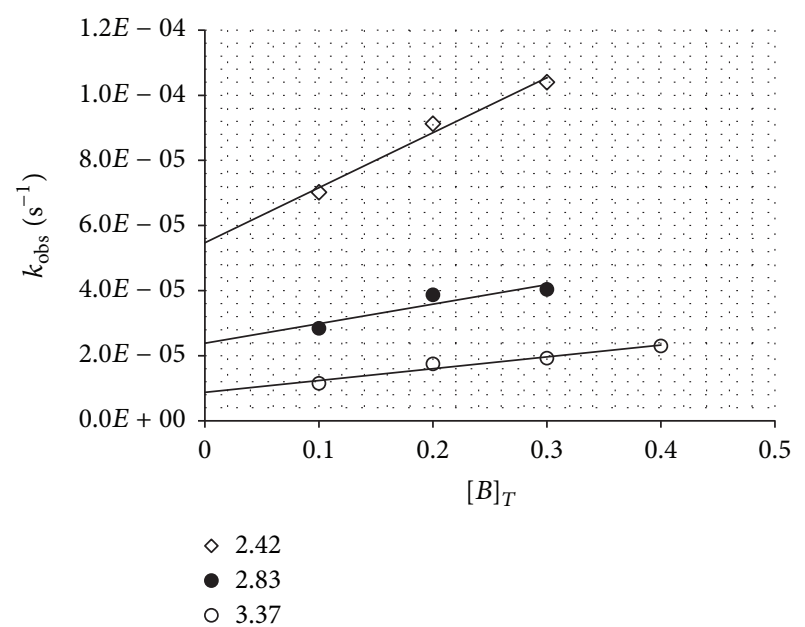

FIgURE 1: The plots of $k_{\mathrm{obs}}=f\left([B]_{T}\right)$ for the degradation of EP in phosphate buffer at $353 \mathrm{~K}$.

3.2. Buffer Catalysis. Under the conditions of this study, the rate constants $\left(k_{\text {obs }}\right)$ depended on the total concentrations of the phosphate and acetate buffers, which indicated that the components of the buffers catalyzed the degradation of EP (general acid-base catalysis). In order to verify that the differences between $k_{\text {obs }}$ determined at different buffer concentrations were statistically significant, the parallelism test was used. Under the conditions of general acid-base catalysis, $k_{\text {obs }}$ were calculated from the following equation:

$$
k_{\mathrm{obs}}=k_{\mathrm{pH}}+k_{B}[B]_{T},
$$

where $[B]_{T}$ is the total buffer concentration, $k_{\mathrm{pH}}$ is the rate constant at zero buffer concentration, and $k_{B}$ describes the catalytic effect of the buffer components. The catalytic effect of the acetate buffer was investigated at $\mathrm{pH} 4.02-5.89$ while those of phosphate buffers were investigated at $\mathrm{pH}$ 2.15-3.40 (Figure 1) and pH 5.91-7.45. Since in the reaction solutions of $\mathrm{EP}$ in $\mathrm{HCl}$ and borate buffer general acid-base catalysis was not observed, in that $\mathrm{pH}$ range, the values of $k_{\mathrm{obs}}=k_{\mathrm{pH}}$.

3.3. $p H$-Rate Profiles. The values $k_{\mathrm{pH}}$ calculated from (2) under the conditions of general acid-base catalysis (acetate and phosphate buffers) and those obtained for hydrochloric acid as well as borate buffer $\left(k_{\mathrm{obs}}=k_{\mathrm{pH}}\right)$ were used to calculate the relationship $\log k_{\mathrm{pH}}=f(\mathrm{pH})$ (Figure 2).

The semilogarithmic relationship $k_{\mathrm{pH}}-\mathrm{pH}$ (Figure 2) indicated that in water solutions at $\mathrm{pH}$ 0.42-9.95 the following reactions occurred:

(i) Degradation of the protonated molecules of EP catalyzed by hydrogen ions $\left(k_{1}\right)$

(ii) Spontaneous hydrolysis of protonated $\left(k_{2}\right)$ and unprotonated $\left(k_{3}\right)$ molecules of EP under the influence of water

(iii) Degradation of unprotonated molecules and monoanions of EP catalyzed by hydroxide ions $\left(k_{4}\right.$ and $k_{5}$ )

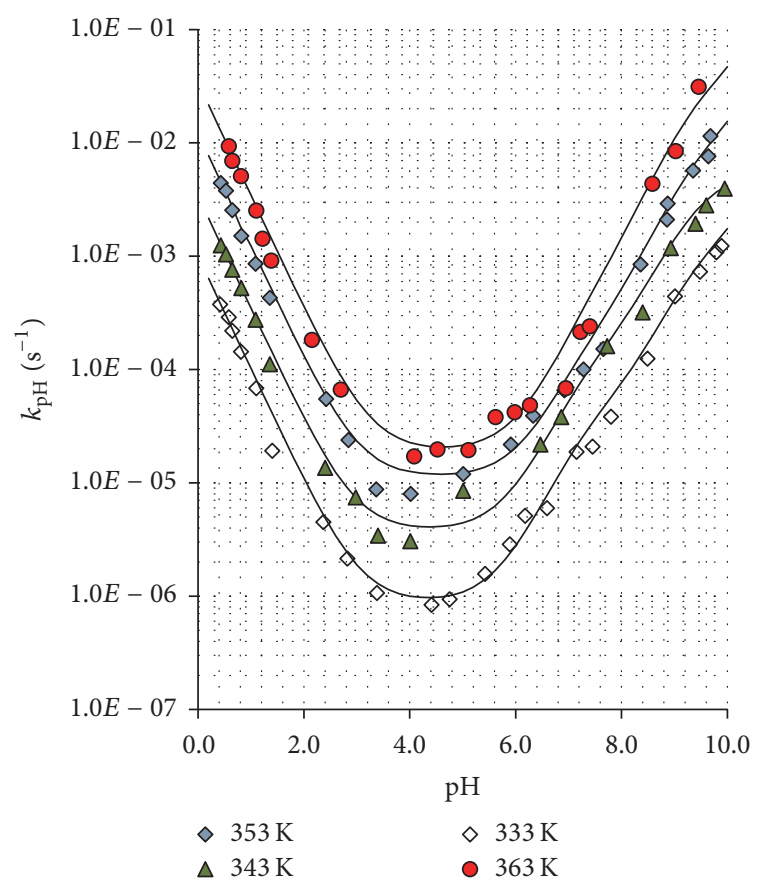

FIGURE 2: The $\mathrm{pH}$-rate profiles for the degradation of EP at 333, 343, 353 , and $363 \mathrm{~K}$. The symbols represent experimental points; the lines were calculated from (3).

The total reaction rate was equal to the sum of partial reaction rates:

$$
\begin{aligned}
k_{\mathrm{pH}}= & k_{1} \times a_{\mathrm{H}^{+}} \times f_{1}+k_{2} \times f_{1}+k_{3} \times f_{2} \\
& +\left(k_{4} \times f_{2}+k_{5} \times f_{3}\right) \times a_{\mathrm{OH}^{-}},
\end{aligned}
$$

where $a_{\mathrm{H}^{+}}$is the hydrogen ion activity and $f_{1}-f_{3}$ are the fractions of protonated and unprotonated molecules and monoanions of EP. The $f_{1}-f_{3}$ values were calculated by using the values of $\mathrm{pK}_{a}$ of EP that were about 7.4 and 9.5.

The catalytic rate constants $\left(k_{1}\right)$ were calculated from the plots $k_{\mathrm{pH}}=f\left(a_{\mathrm{H}^{+}}\right)$by using the values of $k_{\mathrm{pH}}$ in the $\mathrm{pH}$ range $0.42-3.40$. The plots were linear with the positive slope that equaled $k_{1}$ (Figure 3 ).

The catalytic rate constants $k_{4}$ and $k_{5}$ were calculated from the equation $k_{\mathrm{pH}}^{\prime}=k_{\mathrm{pH}}-\left(k_{1} \times a_{\mathrm{H}^{+}} \times f_{1}\right)=\left(k_{4} \times f_{2}+\right.$ $\left.k_{5} \times f_{3}\right) \times a_{\mathrm{OH}^{-}}$using $k_{\mathrm{pH}}$ values above $\mathrm{pH} 8.5$ where the concentrations of $f_{2}+f_{3} \rightarrow 1$. The plots $k_{\mathrm{pH}}^{\prime} /\left(a_{\mathrm{OH}^{-}} \times f_{3}\right)=$ $f\left(f_{2} / f_{3}\right)$ were linear with positive slopes equal to the catalytic rate constant $k_{4}$ and the value $b$ corresponded to the catalytic rate constant $k_{5}$. The catalytic rate constants $k_{2}$ and $k_{3}$ were calculated from the following equation: $k_{\mathrm{pH}}^{\prime}=k_{\mathrm{pH}^{-}}-\left(k_{1} \times a_{\mathrm{H}^{+}} \times\right.$ $\left.f_{1}+\left(k_{4} \times f_{2}+k_{5} \times f_{3}\right) \times a_{\mathrm{OH}^{-}}\right)=k_{2} \times f_{1}+k_{3} \times f_{2}$, using the $k_{\mathrm{pH}}$ values at $\mathrm{pH} 2.8-7$, where the concentrations of $f_{1}+f_{2} \rightarrow 1$.

The plots $k_{\mathrm{pH}}^{\prime} / f_{1}=f\left(f_{2} / f_{1}\right)$ were linear with positive slopes equal to the catalytic rate constant $k_{3}$ and the value $b$ corresponded to the catalytic rate constant $k_{2}$.

The calculated theoretical profile of $\log k=f(\mathrm{pH})$ and that obtained from the experimental results were nearly identical, indicating that the choice of the equation describing the total rate of EP degradation was correct (Figure 2). 
TABLE 1: Catalytic rate constants and thermodynamic parameters for the degradation of EP in aqueous solutions.

\begin{tabular}{|c|c|c|c|c|}
\hline Catalytic rate constant & Temperature (K) & $(k \pm \Delta k)$ & $\begin{array}{l}\text { Parameters of regression } \\
\qquad \ln k_{i}=f(1 / T)\end{array}$ & Thermodynamic parameters \\
\hline \multirow[t]{4}{*}{$\begin{array}{l}k_{1} \\
\left(\mathrm{~mol}^{-1} \mathrm{~L} \mathrm{~s}^{-1}\right)\end{array}$} & 333 & $(1.02 \pm 0.07) \times 10^{-3}$ & $r=-0.9997$ & $E_{a}=118.8 \pm 9.4\left(\mathrm{~kJ} \mathrm{~mol}^{-1}\right)$ \\
\hline & 343 & $(3.44 \pm 0.12) \times 10^{-3}$ & $a=-14282 \pm 1130$ & $\Delta H^{\neq}=116.3 \pm 9.4\left(\mathrm{~kJ} \mathrm{~mol}^{-1}\right)$ \\
\hline & 353 & $(1.22 \pm 0.11) \times 10^{-2}$ & $b=36.0 \pm 3.3$ & $\Delta S^{\neq}=54.5 \pm 27.0\left(\mathrm{~J} \mathrm{~K}^{-1} \mathrm{~mol}^{-1}\right)$ \\
\hline & 363 & $(3.43 \pm 0.41) \times 10^{-2}$ & & \\
\hline \multirow[t]{4}{*}{$\begin{array}{l}k_{2} \\
\left(\mathrm{~s}^{-1}\right)\end{array}$} & 333 & $(8.82 \pm 8.22) \times 10^{-7}$ & $r=-0.9850$ & $E_{a}=104.1 \pm 55.4\left(\mathrm{~kJ} \mathrm{~mol}^{-1}\right)$ \\
\hline & 343 & $(3.79 \pm 2.75) \times 10^{-6}$ & $a=-12518 \pm 6666$ & $\Delta H^{\neq}=101.6 \pm 55.4\left(\mathrm{~kJ} \mathrm{~mol}^{-1}\right)$ \\
\hline & 353 & $(1.12 \pm 0.85) \times 10^{-5}$ & $b=23.8 \pm 19.2$ & $\Delta S^{\neq}=-46.6 \pm 159.5\left(\mathrm{~J} \mathrm{~K}^{-1} \mathrm{~mol}^{-1}\right)$ \\
\hline & 363 & $(1.91 \pm 1.04) \times 10^{-5}$ & & \\
\hline \multirow[t]{4}{*}{$\begin{array}{l}k_{3} \\
\left(\mathrm{~s}^{-1}\right)\end{array}$} & 333 & $(5.02 \pm 0.42) \times 10^{-5}$ & $r=-0.9890$ & $E_{a}=80.7 \pm 36.7\left(\mathrm{~kJ} \mathrm{~mol}^{-1}\right)$ \\
\hline & 343 & $(1.57 \pm 0.04) \times 10^{-4}$ & $a=-9708 \pm 4416$ & $\Delta H^{\neq}=78.3 \pm 36.7\left(\mathrm{~kJ} \mathrm{~mol}^{-1}\right)$ \\
\hline & 353 & $(2.46 \pm 0.11) \times 10^{-4}$ & $b=19.3 \pm 12.7$ & $\Delta S^{\neq}=-84.0 \pm 105.7\left(\mathrm{~J} \mathrm{~K}^{-1} \mathrm{~mol}^{-1}\right)$ \\
\hline & 363 & $(6.28 \pm 0.52) \times 10^{-4}$ & & \\
\hline \multirow[t]{4}{*}{$\begin{array}{l}k_{4} \\
\left(\mathrm{~mol}^{-1} \mathrm{~L} \mathrm{~s}^{-1}\right)\end{array}$} & 333 & $(4.95 \pm 0.65)$ & $r=-0.9979$ & $E_{a}=66.8 \pm 13.1\left(\mathrm{~kJ} \mathrm{~mol}^{-1}\right)$ \\
\hline & 343 & $(9.89 \pm 1.21)$ & $a=-8042 \pm 1579$ & $\Delta H^{\neq}=64.4 \pm 13.1\left(\mathrm{~kJ} \mathrm{~mol}^{-1}\right)$ \\
\hline & 353 & $(17.6 \pm 8.7)$ & $b=25.7 \pm 4.5$ & $\Delta S^{\neq}=-30.8 \pm 37.8\left(\mathrm{~J} \mathrm{~K}^{-1} \mathrm{~mol}^{-1}\right)$ \\
\hline & 363 & $(37.6 \pm 19.2)$ & & \\
\hline \multirow[t]{4}{*}{$\begin{array}{l}k_{5} \\
\left(\mathrm{~mol}^{-1} \mathrm{~L} \mathrm{~s}^{-1}\right)\end{array}$} & 333 & $(0.821 \pm 3.110)$ & $r=-0.9993$ & $E_{a}=63.8 \pm 7.3\left(\mathrm{~kJ} \mathrm{~mol}^{-1}\right)$ \\
\hline & 343 & $(1.44 \pm 7.17)$ & $a=-7678 \pm 882$ & $\Delta H^{\neq}=61.4 \pm 7.3\left(\mathrm{~kJ} \mathrm{~mol}^{-1}\right)$ \\
\hline & 353 & $(3.10 \pm 24.78)$ & $b=22.8 \pm 2.5$ & $\Delta S^{\neq}=-54.8 \pm 21.1\left(\mathrm{~J} \mathrm{~K}^{-1} \mathrm{~mol}^{-1}\right)$ \\
\hline & 363 & $(5.39 \pm 99.46)$ & & \\
\hline
\end{tabular}

$\Delta H^{\ddagger}$ and $\Delta S^{\ddagger}$ were calculated for $293 \mathrm{~K} . E_{a}=-a R\left(\mathrm{~J} \mathrm{~mol}^{-1}\right) ; \Delta H^{\ddagger}=E_{a}-R T\left(\mathrm{~J} \mathrm{~mol}^{-1}\right) ; \Delta S^{\ddagger}=R[\ln A-\ln (k T / h)]\left(\mathrm{J} \mathrm{K}^{-1} \mathrm{~mol}^{-1}\right)$, where $k$ is Boltzmann's constant $\left(1.3807 \times 10^{-23} \mathrm{~J} \mathrm{~K}^{-1}\right), h$ is Planck's constant $\left(6.626 \times 10^{-34} \mathrm{~J} \mathrm{~s}\right), R$ is the universal gas constant $\left(8.314 \mathrm{~J} \mathrm{~K}^{-1} \mathrm{~mol}^{-1}\right), T$ is temperature in $\mathrm{K}, a$ is the vectorial coefficient of the Arrhenius relationship, and $A$ is the frequency coefficient.

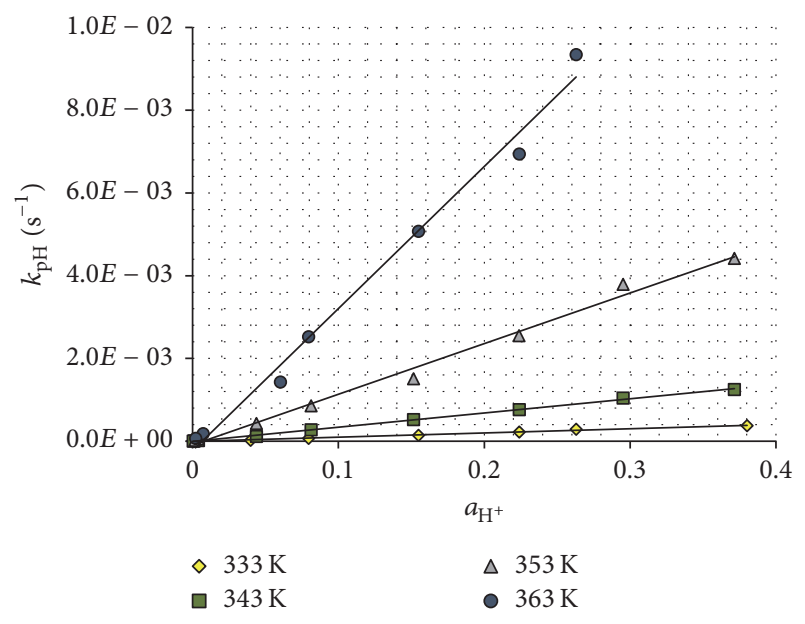

FIgURE 3: The plots of $k_{\mathrm{pH}}=f\left(a_{\mathrm{H}^{+}}\right)$for the degradation of EP in aqueous solutions at the indicated temperatures.

Based on the Arrhenius relationship $\ln k=\ln A-E_{a} / R T$, linear plots of $\ln k=f(1 / T)$ were used to calculate the energy of activation $\left(E_{a}\right)$, the entropy $\left(\Delta S^{\neq}\right)$, the enthalpy $\left(\Delta H^{\ddagger}\right)$, and the preexponential coefficient $(A)$ for the five partial reactions (Table 1).

The lowest energy of activation was observed in the reactions of unprotonated molecules and monoanions of EP catalyzed by hydroxide ions whereas the highest energy of activation was observed in the reaction of protonated molecules of EP catalyzed by hydrogen ions.

3.4. Theoretical Studies. Based on theoretical calculations, the places in EP molecules that might be connected with the differences in EP reactivity in solutions with various $\mathrm{pH}$ values were proposed. The electrons in EP were concentrated in the tetracyclic quinolid aglycone, especially in the $\mathrm{C}$ ring. That domain was responsible for the reactivity of EP during base hydrolysis (Figure 4).

The calculations also indicated that the A ring of the tetracyclic quinolid aglycone played a part in EP susceptibility to degradation during acidic hydrolysis. A comparison of electron distribution in the HOMO and LUMO of EP demonstrated that it was similar to electron distribution in daunorubicin and doxorubicin (Figure 5). Previous stability studies of those three anthracycline antibiotics did not show any statistically significant differences between 


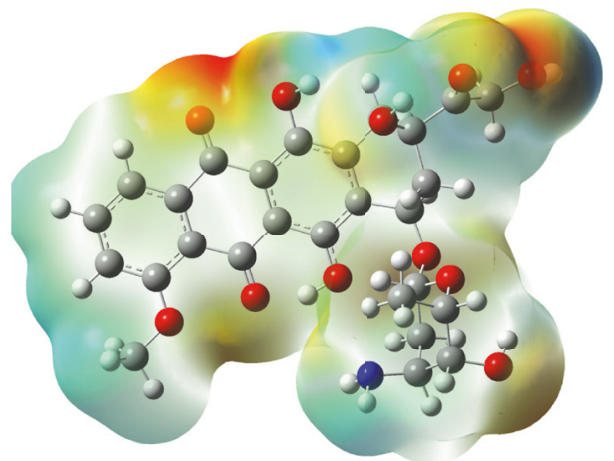

FIgURE 4: ESP of epidoxorubicin.

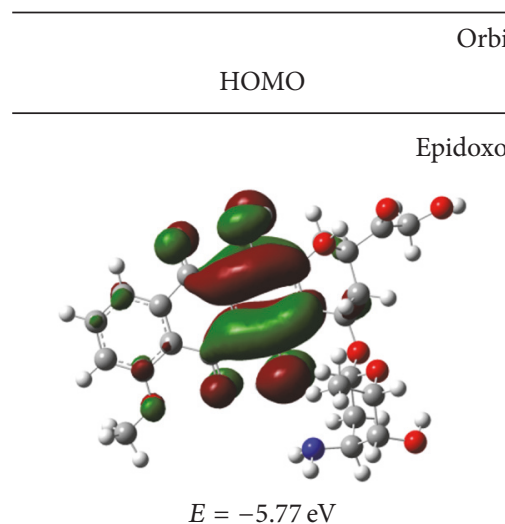

Orbitals

pidoxorubicin 
in stereoisomerism was crucial for ensuring the greater therapeutic safety of EP.

\section{Conflicts of Interest}

The authors declare that there are no conflicts of interest regarding the publication of this paper.

\section{References}

[1] G. Minotti, S. Licata, A. Saponiero et al., "Anthracycline metabolism and toxicity in human myocardium: Comparisons between doxorubicin, epirubicin, and a novel disaccharide analogue with a reduced level of formation and [4Fe-4S] reactivity of its secondary alcohol metabolite," Chemical Research in Toxicology, vol. 13, no. 12, pp. 1336-1341, 2000.

[2] A. Mordente, E. Meucci, G. E. Martorana, B. Giardina, and G. Minotti, "Human heart cytosolic reductases and anthracycline cardiotoxicity," IUBMB Life, vol. 52, no. 1-2, pp. 83-88, 2001.

[3] M. Piekarski and A. Jelińska, "Anthracyclines still prove effective in Anticancer Therapy," Mini-Reviews in Medicinal Chemistry, vol. 13, no. 5, pp. 627-634, 2013.

[4] A. Sobczak, A. Jelińska, M. Leśniewska, A. Firlej, and I. Oszczapowicz, "Stability of epidoxorubicin in solid state," Journal of Pharmaceutical and Biomedical Analysis, vol. 54, no. 4, pp. 869872, 2011.

[5] J. Cielecka-Piontek, A. Jelińska, M. Zajac, M. Sobczak, A. Bartold, and I. Oszczapowicz, "A comparison of the stability of doxorubicin and daunorubicin in solid state," Journal of Pharmaceutical and Biomedical Analysis, vol. 50, no. 4, pp. 576579, 2009.

[6] M. J. Wood, W. J. Irwin, and D. K. Scott, "Photodegradation of doxorubicin, daunorubicin and epirubicin measured by high-performance liquid chromatography," Journal of Clinical Pharmacy and Therapeutics, vol. 15, no. 4, pp. 291-300, 1990.

[7] A. Jelińska, M. Zając, K. Krzystoń, A. Firlej, and I. Oszczapowicz, "The use of HPLC for determining the stability of epirubicin and the influence of ionic strength on the stability of epirubicin," Annales Universitatis Mariae Curie-Skłodowska Lublin - Polonia, vol. 19, no. 2, pp. 45-50, 2006.

[8] M. J. Wood, W. J. Irwin, and D. K. Scott, "Stability of doxorubicin, daunorubicin and epirubicin in plastic syringes and minibags," Journal of Clinical Pharmacy and Therapeutics, vol. 15, no. 4, pp. 279-289, 1990.

[9] D. Kumar, R. S. Tomar, S. K. Deolia, R. Srivastava, M. Mitra, and S. Tyagi, "Isolation and characterization of degradation impurities in epirubicin hydrochloride injection," Journal of Chromatography B, vol. 869, no. 1-2, pp. 45-53, 2008.

[10] E. Pawełczyk and T. Hermann, The Fundamentals of Stability of Drugs, Warsaw, Poland, 1982.

[11] M. J. Frisch, G. W. Trucks, H. B. Schlegel et al., Gaussian 03, Revision D.01, Gaussian, Inc., Wallingford, Conn, USA, 2004.

[12] J. H. Beijnen, O. A. G. J. van der Houwen, and W. J. M. Underberg, "Aspects of the degradation kinetics of doxorubicin in aqueous solution," International Journal of Pharmaceutics, vol. 32, no. 2-3, pp. 123-131, 1986.

[13] J. H. Beijnen, O. A. G. J. van der Houwen, M. C. H. Voskuilen, and W. J. M. Underberg, "Aspects of the degradation kinetics of daunorubicin in aqueous solution," International Journal of Pharmaceutics, vol. 31, no. 1-2, pp. 75-82, 1986. 

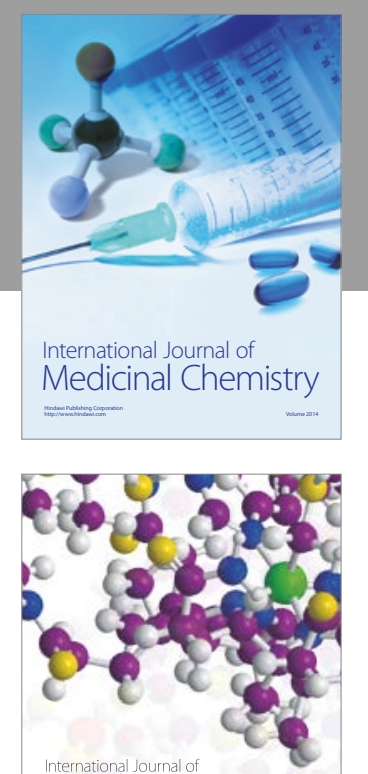

Carbohydrate Chemistry

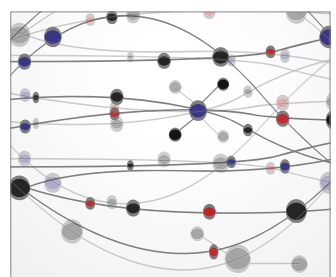

The Scientific World Journal
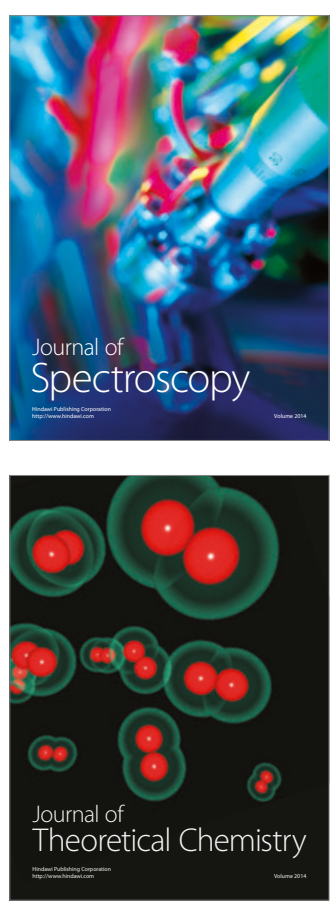
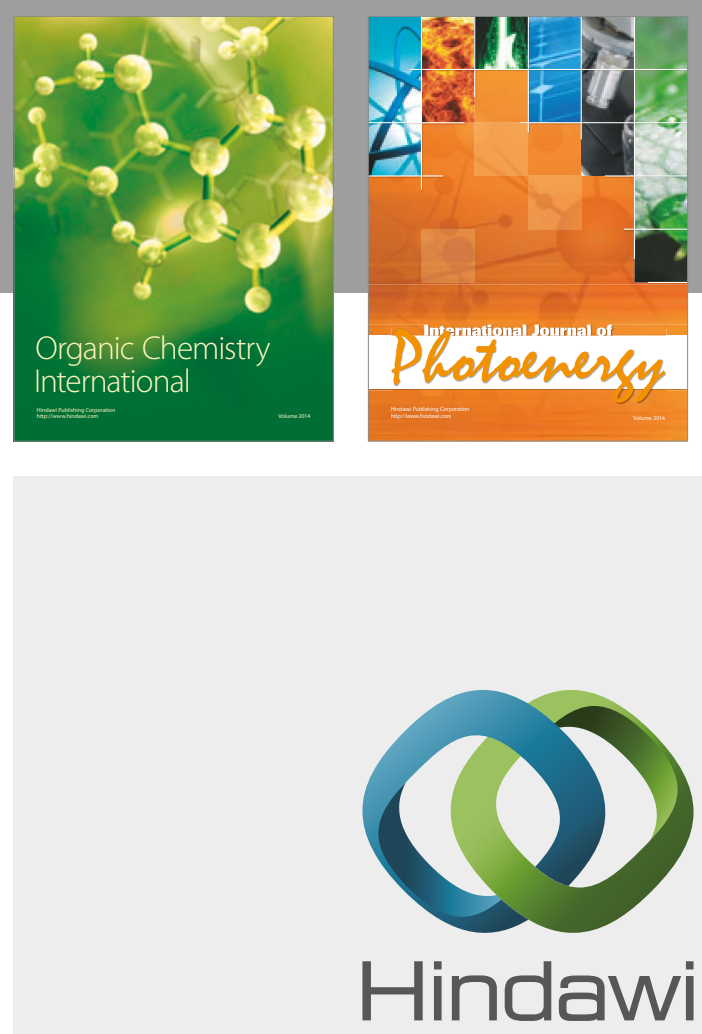

Submit your manuscripts at

https://www.hindawi.com

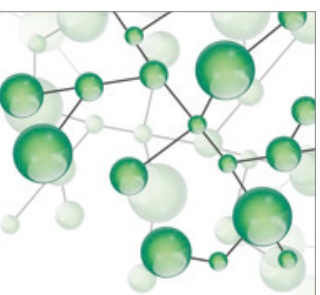

International Journal of

Inorganic Chemistry

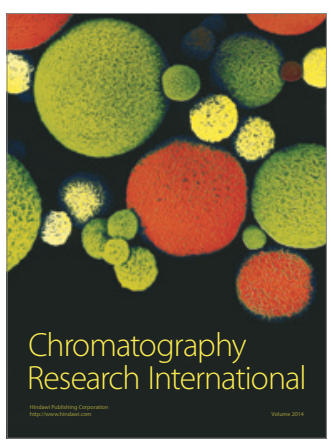

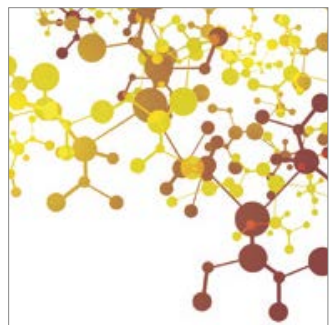

Applied Chemistry
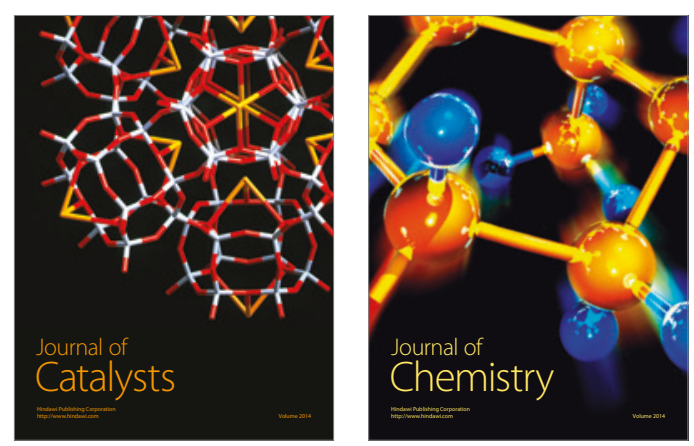
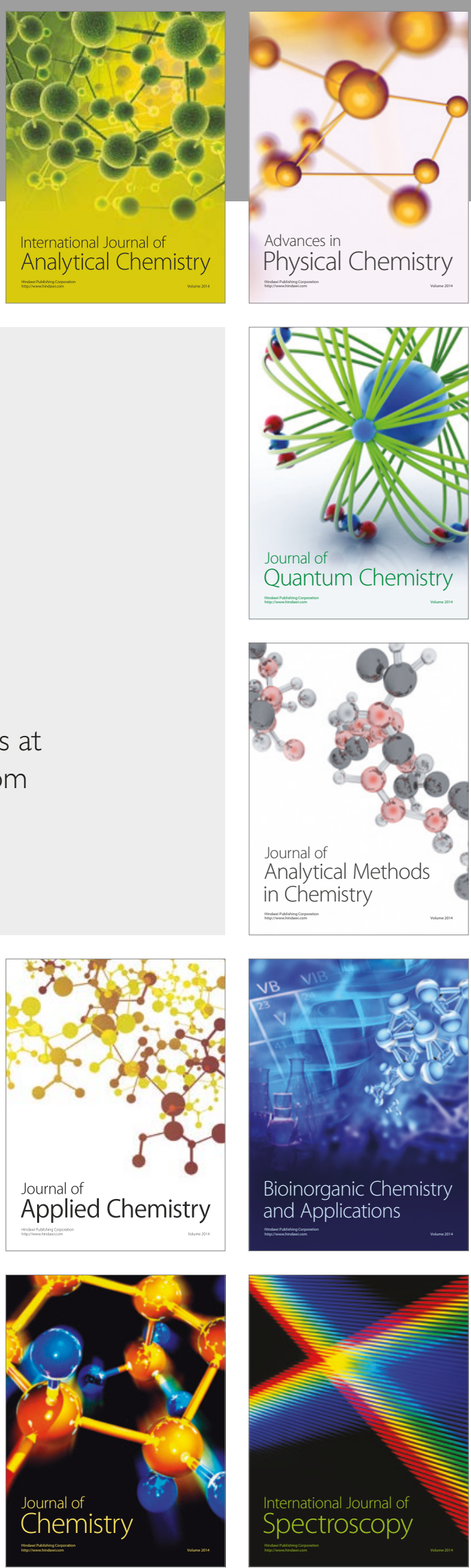